Article

\title{
Assessment of a Nurse Led Energy Behavior Change Intervention in an NHS Community Hospital Ward
}

\author{
Louise Sawyer $^{1}$, Simon Kemp ${ }^{1}$, Patrick James ${ }^{2, *(D)}$ and Michael Harper ${ }^{2}$ \\ 1 Geography and Environmental Science, Faculty of Environmental and Life Sciences, \\ University of Southampton, Highfield, Southampton SO17 1BJ, UK; louise.sawyer@soton.ac.uk (L.S.); \\ s.kemp@soton.ac.uk (S.K.) \\ 2 Sustainable Energy Research Group, National Infrastructure Laboratory, \\ Faculty of Engineering and Physical Sciences, Boldrewood Innovation Campus, University of Southampton, \\ Southampton SO16 7QF, UK; m.harper@outlook.com \\ * Correspondence: paj1@soton.ac.uk; Tel.: +44-238-059-2442
}

Citation: Sawyer, L.; Kemp, S.;

James, P.; Harper, M. Assessment of a Nurse Led Energy Behavior Change Intervention in an NHS Community Hospital Ward. Energies 2021, 14, 6523 https://doi.org/10.3390/en14206523

Academic Editor: Antonio Gagliano

Received: 12 July 2021

Accepted: 21 September 2021

Published: 11 October 2021

Publisher's Note: MDPI stays neutral with regard to jurisdictional claims in published maps and institutional affiliations.

Copyright: (c) 2021 by the authors. Licensee MDPI, Basel, Switzerland. This article is an open access article distributed under the terms and conditions of the Creative Commons Attribution (CC BY) license (https:// creativecommons.org/licenses/by/ $4.0 /)$.
Abstract: This paper investigates a nurse led, energy conservation behavioral intervention, in hospital wards of an NHS (National Health Service) community hospital (Trust). The information based intervention was adapted from "Operation TLC", developed by environmental behavioral change charity Global Action Plan, and St Bartholomew's Health NHS Trust, London. For this study, three identical older persons' acute-care wards in terms of patient type, nursing levels, layout, electrical fittings (lighting \& small power), elevation and orientation (one control ward and two intervention wards) were evaluated over a nine-month period. The paper demonstrates a co-dependent relationship between the quantitative data from the electricity and light monitors on the wards with the qualitative data gathered from staff comfort surveys and focus groups, and Trust policies. Our results show a $13 \%$ reduction in electricity consumption, primarily from preventing nursing staff in the intervention group from using prohibited secondary space heaters at night during the heating season and the introduction of a "quiet time" in the intervention group. During quiet time lights in the intervention group were turned off for an hour after lunch to encourage rest for patients to provide time for nursing staff to complete administrative tasks. Electricity reductions achieved during the intervention period were observed to continue into the 3-month post intervention period but at a reduced level.

Keywords: hospital; energy behavioral change; indoor environment; patients; nursing staff

\section{Introduction}

The Climate Change Act 2008, imposed a mandatory target for the UK to reduce its greenhouse gases by $80 \%$ by 2050 from a 1990 baseline [1]. Alongside increasing concerns about the effects of a changing climate on our health and care system [2,3], the National Health Service (NHS) in England has publically committed to reduce its carbon footprint (scopes 1, 2 and 3) by 34\% by 2020 from a 2007 baseline [4]. The NHS England's 2015 carbon footprint was 22.8 million tonnes of carbon dioxide equivalent (MtCO2e) with energy accounting for $20 \%$ of the footprint or $4.6 \mathrm{MtCO} 2 \mathrm{e}$ [5]. In 2015/16, NHS Trusts in England spent over $£ 570$ million on energy and consumed over 10,983,151 megawatt hours (MWh) of energy [6]. To help facilitate energy reduction and put climate change mitigation at the heart of the health service, the Department of Health (DoH) published Health Technical Memorandum (HTM) EnCO2de 2015 [7]. EnCO2de 2015 provides advice and guidance to healthcare organizations on how to consider the implications of energy use and carbon reduction whilst putting patients first [7]. 
Behavior change features more prominently in EnCO2de 2015 than in previous versions with the publication acknowledging the importance of staff behavior change and motivation on the impact of healthcare organizations' ability to save energy, particularly where energy savings are not the main priority of staff [7].

The Carbon Trust [8] states that a well implemented staff engagement scheme can lead to energy savings of between $5-10 \%$. Since the beginning of the financial year 2012/13, forty eight NHS general acute-care hospitals have reported implementing a staff centered energy conservation initiative. However, only eight could provide an estimated cost saving from their initiative, which ranged between 1-5\% of total energy cost [9] although none of these savings were verified.

Operation TLC is an energy behavior change programme developed by Global Action Plan (GAP), an environmental behavioral change charity and St Bartholomew's Health NHS Trust. Operation TLC stands for Turn equipment off, Light out \& Control temperatures and was developed to deliver an improved experience for staff and patients, improved environments and cost efficiencies in NHS organizations (Trusts) [10]. Whilst energy behavior change in households has been considerably studied [11,12], energy behavior change in organizations has been studied to a lesser extent [13] and energy behavior change in healthcare has been scarcely studied at all [14]. Furthermore, very little research has been undertaken on the performance outcomes of behavior change interventions [15], particularly in healthcare organizations [9] making it difficult to calculate the effectiveness of these interventions [16].

A thorough literature review on 'energy in healthcare' highlighted a number of academic publications on the topic $[9,11]$. These articles predominately focus on direct hospital energy usage from reported healthcare accounts [17-19], identification of the highest energy use activities and equipment within hospitals [20-22] and, retrofitting and designing sustainable healthcare buildings $[7,14,22,23]$. There are a number of academic publications that report on the topic of 'pro-environmental behavior in hospitals' [14,24]. Whilst some of this work may be utilized in an energy behavior change intervention, a thorough review of relevant literature on 'employee energy behavior change', 'energy employee engagement' and 'employee-centered energy conservation interventions in hospitals, healthcare and NHS' revealed only two direct academic publications on the topic. The first publication by Morgenstern et al. [9] discusses the "applicability, potentials and limitations of employee-centered energy conservation interventions in English hospitals" and the second publication by Manika et al. [11] discusses the "effects of an energy saving intervention in two hospitals". This paper investigates the effects of running a nurse led behavioral intervention on energy conservation in a NHS community hospital in the South of England. The hypothesis is that through raised awareness, behavior change o front line nursing staff can reduce the energy demands of they operate in. The aim is to inform NHS building managers, environmental consultants and social scientists on the effectiveness of running a low-cost, easy-to-implement nurse led behavior change intervention aimed at reducing energy consumption in a NHS hospital whilst putting patients first.

This study forms part of a wider project which uses qualitative (staff comfort surveys and staff focus groups) and quantitative (energy consumption, air temperature, relative humidity, noise, carbon dioxide, artificial lighting, window movements and patient bed movements) data collection methods to measure the potential sustainability (financial, environmental and social) benefits for patients, staff and the organization of running an energy behavior change intervention $[25,26]$. The intervention is adapted from Operation TLC to older persons' acute-care wards in an NHS community hospital.

Energy behavior change interventions comprise a variety of approaches often used in combination with each other including information, feedback, setting goals and rewards [27]. Information based energy behavior change interventions are the most popular form of intervention [27] and are more effective when the information is tailored to the specific audience, particularly when the behavior change is relatively convenient and not 
costly in terms of money, time or effort [28]. However, these type of campaigns usually only result in modest behavioral change [28] and associated modest savings [29].

Feedback at both the individual and group level is often used as an approach to encourage energy conservation behaviors in both domestic and non-domestic settings $[27,30,31]$ and has the greatest success when delivered in a simple way as close to the behavior change intervention as possible $[29,32]$. In non-domestic settings comparative feedback was found to encourage greater energy savings than individual feedback [32-34]. Nolan et al. [35] found that significant energy savings were achieved when staff were given information about energy conservation behavior of others in the intervention group.

In both domestic and non-domestic settings energy behavior change was found to diminish when feedback stopped, so continued engagement is required to maintain energy conservation [36,37]. In non-domestic settings, engagement in feedback was found to diminish over time [33], although energy savings took longer to take hold [27,38]. Some studies found benefits from combining feedback with setting challenging, but still achievable goals, in both domestic and non-domestic settings [30,39]. The use of incentives or rewards is sometimes used as an approach to encourage behavior change. Studies found that incentives usually fell into two categories, (1) financial rewards such as cash, bonuses, prizes or (2) social rewards such as goal-setting, points or public praise [40]. Handgraaf et al. [41] found rewards that were given publically outperformed rewards that were given privately, and that social rewards outperformed financial rewards. The studies concluded that incentives or rewards were successful at delivering energy savings but the savings were short lived [40].

In non-domestic settings, the key factors which influence energy conservation include organizational, contextual and social factors $[9,13,29,42]$. The complex interactions between these factors [43] have the potential to both provide leverage to encourage energy efficient behaviors and create barriers to hinder energy efficiency behaviors [42]. Organizational factors include organizational culture, policies and practices. Siero et al. [32] and Mulville et al. [27] found it was more effective to focus on workplace culture and practices than the attitude of the employees involved in the intervention. As a captive audience, employees are subject to organization policy and practices [29]. Energy conservation polices are more acceptable when they promote energy efficiency rather than restrict behaviors [28] and are directed to staff who value the environment or feel obliged to reduce energy use [44]. Policies must be communicated well to avoid confusion about the contents and desired policy outcome [45]. Senior management commitment [46,47] and active engagement of middle managers [13] are an essential part of organizational culture to deliver energy behavior change.

Differing priorities, objectives and a narrow professional focus may be a barrier to running an energy behavior change initiative [48], particularly if energy conservation priority is perceived to be counterproductive to other primary objectives [14,47,49]. In healthcare organizations, energy conservation is a low priority for healthcare professionals and in some cases is perceived as being in conflict with their main priority of delivering excellent patient care $[9,14]$. Similarly, workload and resources [50] may also be barriers to energy conservation, particularly where workloads are high and/or resources are low $[9,14]$. Contextual factors include lack or limited control over their environment [34,40,48,51,52], power consuming equipment $[24,27,42]$ and direct financial accountability $[14,47,49]$ leading to staff feeling disconnected with energy conservation at work [27]. Consequently, collaboration between all stakeholders in an organization is essential [14,53]. Menzes et al. [54] found a direct relationship between perceived behavioral control and energy use, in that people who had high perceived control saved more energy than those who did not, although in later studies Mulville et al. [27] found this relationship was not as significant as previously expected.

Social factors include social or group norms, knowledge and values. There is evidence that social or group norms may motivate employees to save energy [40,49], particularly when the employees seek praise or reward [55], when encouraged by peers [40,49] and their actions are visible to peers [49]. However, if the culture of the social or group norm is 
anti-environmental then this may discourage energy conservation [49]. Studies have also shown that social or group norms can create separation between personal and professional values and actions, which may lead to cognitive dissonance [24,48,56]. Festinger's [57] cognitive dissonance is the conflict between opposing elements, in this case a person's values and the group's norm.

Ignorance or lack of knowledge has been found to be a barrier to pro-environmental behavior [24,58] with some organizations relying on employees' self-policing pro-environmental behavior based on assumed knowledge that in practice may be lacking [59,60]. Tudor et al. [61] found that employee attitude, particularly in relation to the value placed on the environment and job satisfaction affected behavior change interventions. Likewise, Morgenstern, Raslan, et al. [9] found that energy managers believed participation in energy behavior change interventions was strongly linked to the attitude of individual employees.

Most studies have concluded that whilst an individual's attitudes, beliefs and approach may be transferrable to the workplace [27], a study by Menzes et al. [54] found that attitude did not significantly impact energy use, which confirms studies in non-domestic settings that changes in habit may occur without a change in attitude [32,62]. Despite this, organizations can make use of individuals' personal pro-environmental values through the use of green or environmental champions to encourage their peers to adopt energy conservation $[9,29,50]$.

\section{Materials and Methods}

For this paper, the quantitative electricity data gathered from current clamps on the lighting and small power electrical distribution boards of the control and intervention wards, and data from light monitors in the study wards was analyzed using R [63]. The studied wards, as in the case of the majority of NHS hospitals, have little or no Internet-of-Things based automation. Furthermore, the funding mechanism used in the NHS estate often utilizes complicated service contracts, which makes retrofitting systems potentially very expensive and a behavior change approach as per this study more desirable in terms practical delivery. Ethics approval was granted for the study by the Health Research Authority [25].

Michie et al. [64] concluded that a behavioural change intervention typically starts with deciding what approach to take and then designing the specifics of the intervention itself [64]. This study used an information based behaviour change approach, modelled from an adapted version of Triandis' Theory of Interpersonal Behaviour, shown in Figure 1.

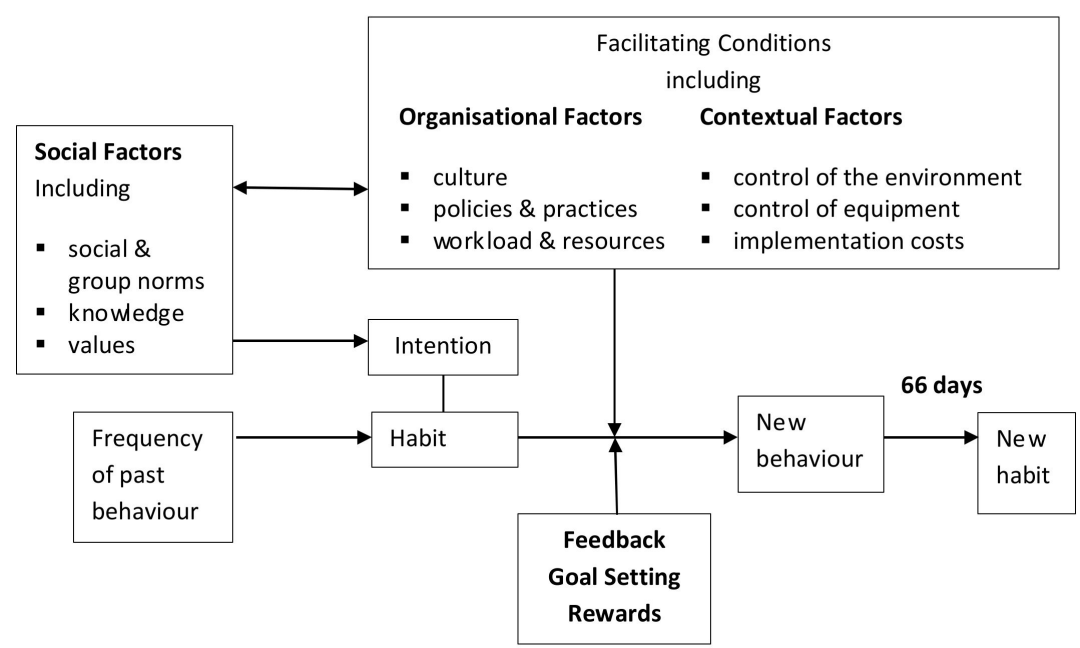

Figure 1. Model of the behavior change approach used in a NHS community hospital adapted from a revised version of Triandis' Theory of Interpersonal Behavior reproduced in Chatterton, 66 day training period [55]. 
The model reflects that in non-domestic settings the key factors influencing energy conservation include organizational, contextual and social factors $[9,13,29,42]$ highlighted in the literature review and the complex interactions between these factors [43]. Theoretically, this study identified the social, organizational and contextual factors in the ward environment affected by the energy behavior change intervention. Methodologically, this study proposed a new model for running a behavior change intervention in hospitals.

The specifics of the intervention itself were based on an adapted version of GAP's Operation TLC energy behavior change intervention. Operation TLC focuses on delivering an improved environment for patients and staff based around three primary actions Turn off equipment, Lights out and Control temperatures and behind these three primary actions lay up to twelve secondary actions, shown in Table 1.

Table 1. Operation TLC staff actions adapted for use in the intervention wards during the behavior change study at the NHS community hospital participating in the study.

\begin{tabular}{ccc}
\hline Primary Action & Secondary Actions & The Intervention \\
\hline $\begin{array}{l}\text { Turn off equipment } \\
\& \text { unwanted noise }\end{array}$ & Turn off any unwanted & Included \\
& medical equipment where possible. & Turn off computers, monitors \\
and TVs that aren't being used. & Included \\
& Switch off lights in unoccupied rooms. & Included \\
Open blinds and make the most of & Included \\
nights out & natural light by switching main lights off. & Included \\
& Introduce quiet time for an hour after lunch. & Included \\
& Switch lights off at night. & Excluded \\
& Close the doors to patient rooms. & Included \\
Control & Close door when rooms aren't occupied. & Excluded \\
temperatures & Control heating gradually. & Included \\
& Layer up if cold. & Included \\
\hline
\end{tabular}

Manika et al. [11] identified there is currently a research gap of linking an energy behavior intervention to the respective hospital building, processes and interfaces with the occupants. Consequently, GAP's Operation TLC behavior change approach was adapted to take into consideration the processes and interfaces of the occupants in the older-persons' acute-care in-patient wards involved in this study, as shown in Table 1.

These changes included (1) the primary action 'Turn off equipment' was changed to 'Turn off equipment and unwanted noise', as noise was reported by Royal College of Nursing [65] as the primary concern for patients about the hospital environment. A study by Park et al. [66] found that $86 \%$ of patients surveyed reported having "bad sleep" as a direct consequence of noise on the ward.

As a community hospital with elderly and often vulnerable patients, the Operation TLC champions took the decision to (2) remove the secondary action "Close the doors to patient rooms" for safety reasons. Also, as staff in the intervention wards have no direct control over the heating systems in their wards, the Operation TLC champions took the decision to (3) remove the secondary action "Control heating gradually" to avoid the staff feeling detached from their work space [48,51] and disconnected with energy conservation at work [27]. The provision of accessible heating control is a clear recommendation in such buildings.

To run a successful energy behavioral change intervention with nursing staff it is essential that patient care is at the heart of the intervention [9] and energy savings is a low-priority as it is sometimes perceived by the clinical staff as being in conflict with their main priority of delivering excellent patient care [14]. Therefore, improving patient care was promoted as the main outcome of the intervention and energy saving was referred to as a secondary outcome.

Operation TLC is an information based energy behavior change intervention, which is one of the most popular forms of behavior change interventions [27]. As evidence based practice is popular amongst healthcare professionals [67], the information provided during the intervention was based on evidence based academic research, which demonstrated the 
intervention actions will improve the health and wellbeing of the patients and staff in the intervention wards.

To prevent environmental numbness from a lack of knowledge and resources $[9,14,48,50,56]$ staff on the intervention wards were provided with a collection of informative tools including cards, posters, stickers and thermometers. To demonstrate the commitment of the senior and middle management team $[46,47]$ to the behavior change intervention and to enthuse the ward staff to participate in it, a launch and Operation TLC training event was organized for the staff away from the ward environment with refreshments and food. The event was attended by the on-site senior and middle management team, together with representatives from the hard facilities provider, the soft facilities provider, nurses, healthcare support workers and housekeeping staff from the two intervention wards to show both peer [48] and management involvement, and collaborative working across stakeholder groups [14,53].

Refresher training and feedback sessions $[26,29,30]$ were incorporated into monthly scheduled intervention ward team briefs in order to overcome issues around workload and resources [50]. During the feedback sessions staff were given social rewards, including public praise as social rewards out performed financial rewards and awards that were given publically out performed rewards that were given privately [41], as well as incentives including promotional pens and "thank-you" heart chocolates.

It takes around sixty-six days for a behavior to become a habit [68], therefore the behavior change intervention was actively run for three months (1 November 201731 January 2018) and was then monitored for further three months post-intervention (1 February-30 April 2018) to assess whether the behavior changes remained consistent or tailed off after the intervention period.

The study took place across 2017-2018 in three identical older-persons' acute-care wards on the same patient type, nursing levels, layout, electrical fittings (lighting \& small power), elevation and orientation (East façade), in a NHS community hospital in the South of England. Small power in the context of this study refers to unfixed equipment and appliances plugged into the electrical network of the building. The wards accommodate older person in-patients requiring acute care, containing both male and female patients (approximately 50:50 split) aged over 65, some of which (on average $27.5 \%$ ) have mental health conditions such as dementia and Alzheimer's. These figures were obtained from the Trust's management information reporting system [69], accessed on 1 August 2018. Two of the greatest current challenges for the NHS, outside of COVID-19, are the growth of mental health illness in society [70] and an ageing population [71], so these wards are significant in terms of NHS patient demographics.

Each ward comprised of four single patient rooms and two 4-bed patient bays; a total of twelve patients on each ward; with a total floorspace area of $393 \mathrm{~m}^{2}$ (patient areas $207 \mathrm{~m}^{2}$, corridor $100 \mathrm{~m}^{2}$, other rooms $85 \mathrm{~m}^{2}$ ). A schematic of the floorplan of a single room and 4-bed patient bay showing the location of the monitors used during the wider project is shown in Figure 2.

Staffing levels were identical on the three wards, comprising ten nursing staff (1 ward manager, 1 ward supervisor, 4 nurses and 4 healthcare support workers) on each ward; a total of 30 nursing staff were involved in the wider project. The occupancy level of the wards was high throughout the study period (as is the case with most NHS wards). It is to be expected that shared services such as lighting and small power would effectively be independent of ward occupancy within normal upper and lower bounds.

Table 2 shows the sensors used to collect quantitative data for the identified energy factors. The monitoring approach is outlined in the following subsections. Additional methods and monitoring detail relating to the wider study is available via [26]. 
Table 2. Energy sensor specifications (accuracy, resolution, sampling rate) for electricity and lights.

\begin{tabular}{ccc}
\hline Parameter & Sensor & Measurement \\
\hline $\begin{array}{c}\text { Electricity } \\
\text { (small power } \\
\& \text { lighting) }\end{array}$ & $\begin{array}{c}\text { Split core LEM AC current AT-B10 } \\
\text { [72] attached to a MadgeTech Volt101A } \\
\text { data logger }\end{array}$ & $\begin{array}{c}\text { Accuracy } \pm 1.5 \%, \\
\text { Resolution } \pm 0.5 \%\end{array}$ \\
& Single measurement every minute \\
\hline Lights & $\begin{array}{c}\text { Unbranded silicon photodiodes, } \\
\text { calibrated against a class 1 LICOR } \\
\text { cosine corrected silicon photodiode } \\
\text { [73], each attached to a } \\
\text { MadgeTech Volt101A data logger }\end{array}$ & $\begin{array}{c}\text { Accuracy } \pm 1.5 \%, \\
\text { Resolution } \pm 0.5 \%\end{array}$ \\
& Single measurement every minute \\
\hline
\end{tabular}
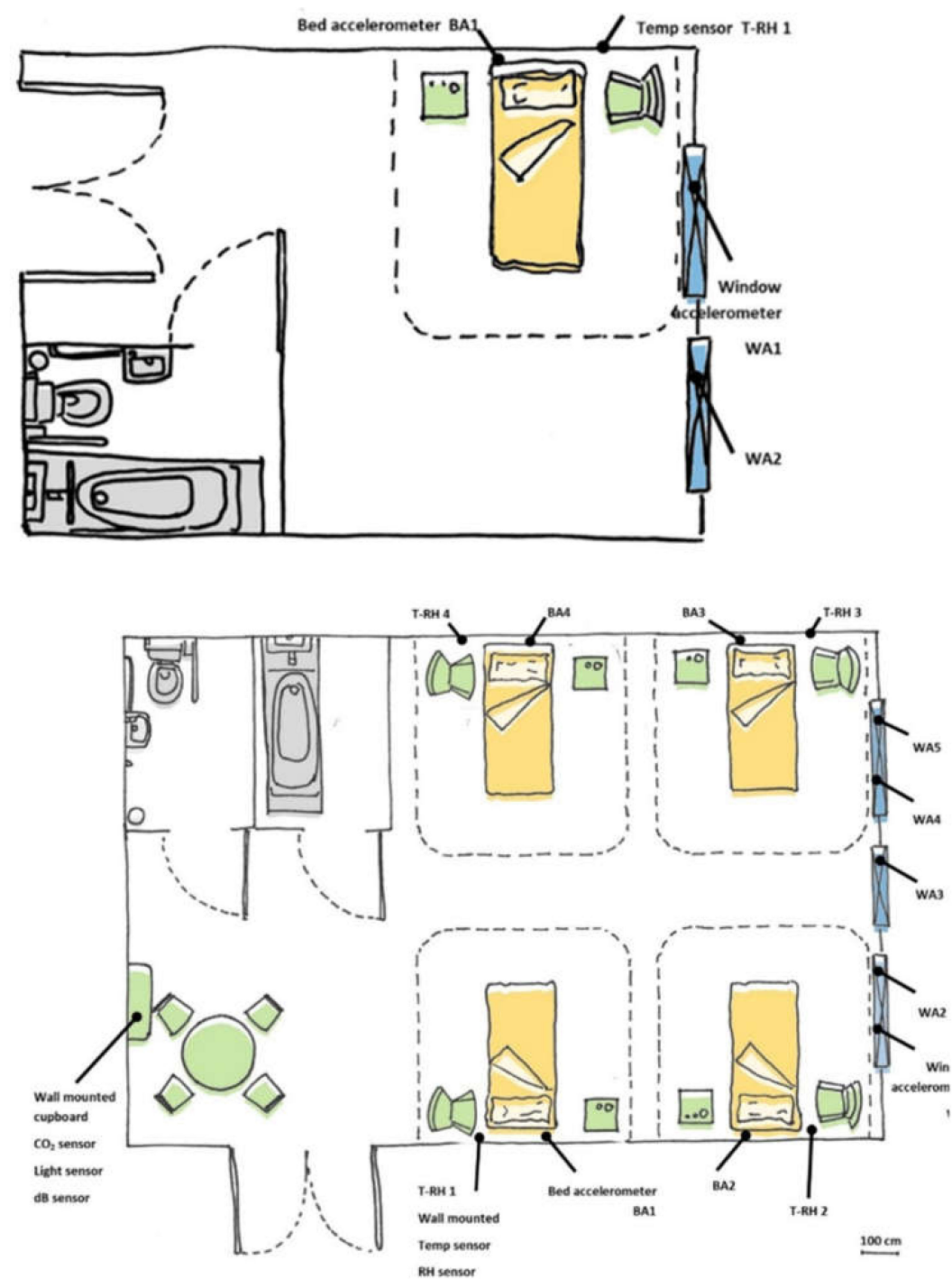

Figure 2. Study single room (TOP) and 4-bed patient bay layout (BOTTOM) and location of measuring equipment used on an older persons' community hospital patient bay to measure the environment over the study (1 August 2017-30 April 2018). WA1 to WA5 = window accelerometers, BA1 to BA4 $=$ bed accelerometers, T-RH 1 to T-RH 4 = air temperature and relative humidity monitors.

The study measured electricity use via a set of three LEM split core current clamps (0-50 A, 0-10 V DC output) [72] attached to a MadgeTech Volt101A data logger. A set of current clamps and logger was fixed to the 3-phase electricity supply on the lighting distribution board and the small power distribution board for each of the three wards. The loggers were set to single measurement with a sampling frequency of every minute. 
Morgenstern, Li, et al. [47] reported that the electrical and heating layout in hospitals does not always correspond with the ward layout, making it extremely challenging to measure the impact of the running the intervention on energy usage at ward level. Whilst the wards have independent electricity supplies for lighting and small power they share a common heating system, therefore the wider project was unable to quantitatively measure the impact of the behavior change intervention on gas consumption.

Nine unbranded silicon photodiodes, calibrated against a class 1 LICOR cosine corrected silicon photodiode [73], each attached to a MadgeTech Volt101A data logger, were used to quantitatively measure if the lights were "on", "dimmed" or "off" located on top of a wall-mounted cupboard on the wall furthest from the windows in each of the four-bed patient bays. The loggers were set to single measurements with a sampling frequency of every minute.

As the light sensors do not distinguish between daylight and artificial light, this approach is only valid for the winter months and will over-predict the 'lights on' values during the summer months when daylight lux levels exceed that produced from artificial lighting. Consequently, the data for the period before the intervention was disregarded from the study. However, as the intervention was run during the winter months this approach was suitable for analyzing the light data in the periods during and after the intervention.

Ethics approval was granted for the study by the Health Research Authority, 'Sustainability benefits of behavioral change in NHS Trusts', IRAS 223344, REC 17/HRA/1897. No personal data was collected from patients, the level of patient information was limited to defining if a studied patient bay was male or female. Nurses provided written consent for participation in the qualitative aspect of the study.

\section{Results}

\subsection{Electricity}

Figure 3, shows the electricity consumption (kWh/day) for (a) lighting and (b) small power for the study periods before, during and after the intervention for the control and intervention study groups. The error bars shown represent one standard deviation.

(a) Lighting

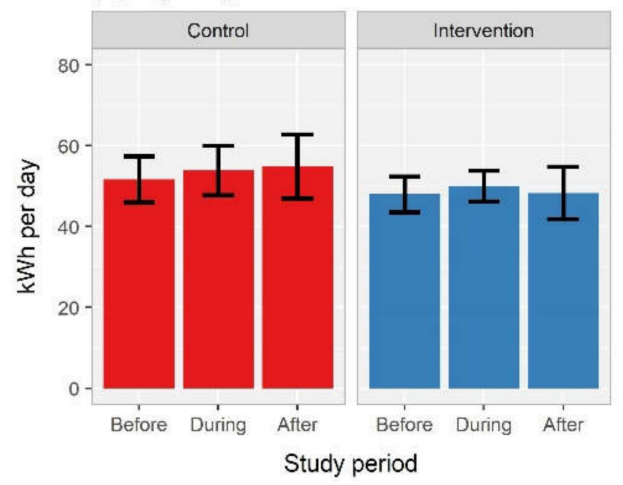

(b) Small Power

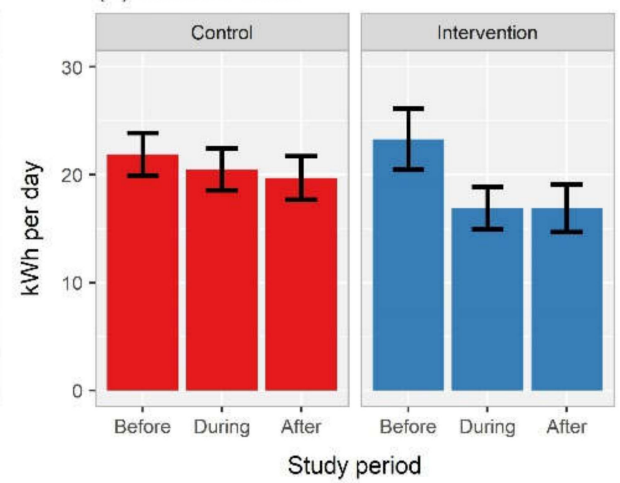

Figure 3. Mean electricity consumption per day ( $\mathrm{kWh} /$ day) for (a) lighting (b) small power, comparing the control and intervention study groups for the study periods before (1 September31 October 2017), during (1 November 2017-31 January 2018) and after (1 February-30 April 2018) the behavior change intervention. 1 Standard Deviation of the mean is shown.

Before the intervention, the control group used a mean of $51.7 \mathrm{kWh}(\sigma=5.7, \mathrm{n}=61$ days $)$ of electricity for lighting per day and the intervention group used $48.0 \mathrm{kWh}(\sigma=4.4)$ per day, a difference of $3.7 \mathrm{kWh}$ per day. The number of fixed light fittings in each ward is identical and therefore the $\mathrm{kWh}$ per day would be expected to be the same during the prior period. Observed differences may be due to a combination of (i) faulty compact florescent tubes which have yet to be changed and/or (ii) the removal of some tubes in some areas to reduce lighting intensity creating asymmetry between the wards. 
During the intervention, the control group used $53.9 \mathrm{kWh}(\sigma=6.2, \mathrm{n}=92$ days) of electricity for lighting per day and the intervention group used 50.0 kWh $(\sigma=3.8)$ per day, a difference of $3.9 \mathrm{kWh}$ per day. After the intervention, the control group used $54.9 \mathrm{kWh}(\sigma=7.9, \mathrm{n}=89$ days $)$ of electricity for lighting per day and the intervention group used $48.3 \mathrm{kWh}(\sigma=6.5)$ per day, a difference of $6.6 \mathrm{kWh}$ per day. Taking a difference of differences (DoD) approach, none of these observed changes between the control and intervention groups can be considered as significant.

Before the intervention, the control group used a mean of $21.9 \mathrm{kWh}(\sigma=2.0)$ of electricity for small power per day and the intervention group used $23.3 \mathrm{kWh}(\sigma=2.8)$ per day, the intervention group being higher by $1.4 \mathrm{kWh}$ per day. During the intervention, the control group used $20.5 \mathrm{kWh}(\sigma=1.9)$ of electricity for small power per day and the intervention group used $16.9 \mathrm{kWh}(\sigma=2.0)$ per day, the intervention group being lower by $3.6 \mathrm{kWh}$ per day. After the intervention, the control group used $19.7 \mathrm{kWh}(\sigma=2.0)$ of electricity for small power per day and the intervention group used $16.9 \mathrm{kWh}(\sigma=2.2)$ per day, the intervention group being lower by $2.8 \mathrm{kWh}$ per day.

Again taking a difference of differences approach, for small power for the control group, the mean changes by $-1.4 \mathrm{kWh}(\sigma=2.8)$ between the before and intervention periods and $-2.2 \mathrm{kWh}(\sigma=2.8)$ between before and after periods. In contrast, for the intervention group, the mean changes by $-6.4 \mathrm{kWh}(\sigma=3.4)$ between the before and intervention periods and $-6.4 \mathrm{kWh}(\sigma=3.4)$ between before and after periods. A Mann Whitney U-test (95\% confidence) showed that this is a statistically significant difference.

The descriptive analysis of electricity used for (a) lighting and (b) small power showed the intervention produced (a) $2 \%$ saving in electricity for lighting relative to the control during the intervention and 10\% saving after the intervention relative to the control, and (b) $29 \%$ saving in electricity for small power during the intervention relative to the control and a $16 \%$ saving after the intervention relative to the control. The control and intervention wards values during the prior period are taken as the reference.

Figure 4 shows the mean daily profiles for (a) lighting and (b) small power for the study periods before, during and after the intervention for the control and intervention study groups. The intervention group had a lower power demand for lighting than the control group across each study period but the difference between the control group and the intervention group appears to have increased following the implementation of the behavior change intervention.

Before the intervention, the intervention group had a higher power demand for small power than the control group and a lower power demand for small power than the control group during and after the intervention.

Figure 4a shows a dip in lighting power demand in the intervention group in the study period during and after the intervention, which coincides with the secondary Operation TLC action of "Introduce a quiet time for an hour after lunch" that was scheduled to occur daily between 13:30:00-14:30:00 (see arrow (i)). Another distinctive feature, shown in Figure 4, is the markedly higher power demand for (b) small power for several hours in the control group over the night-time period during the intervention when compared to the intervention group, which is explored further in the discussion (see arrow (ii)).

When the electricity consumption for lighting and small power is combined, Figure 5 shows that before the intervention, both the control and intervention groups used $72 \mathrm{kWh}$ of total electricity use per day for lighting and small power. Both during and after the intervention, the control group used $77 \mathrm{kWh}$ of total electricity use per day for lighting and small power and the intervention group used $67 \mathrm{kWh}$ per day, a difference of $10 \mathrm{kWh}$ per day. Morgenstern [74] has shown that lighting loads are the dominant electrical demand in UK hospital acute care wards, which is also seen here. Energy benchmarking of UK acute care hospital wards shows small power and lighting loads varying between 7 and $15 \mathrm{~W} / \mathrm{m}^{2}$ over a $24 \mathrm{~h}$ period [47]. For the $393 \mathrm{~m}^{2}$ control ward, the $77 \mathrm{kWh}$ per day corresponds to an average of $8 \mathrm{~W} / \mathrm{m}^{2}$. The DETR guide "ECG72, Energy consumption in hospitals" (1999) 
provides appropriate benchmarks [75] for lighting of $4.6 \mathrm{~W} / \mathrm{m}^{2}$ and $1.6 \mathrm{~W} / \mathrm{m}^{2}$ for small power, which together at $6.2 \mathrm{~W} / \mathrm{m}^{2}$ is close to the observed values.

(a) Lighting

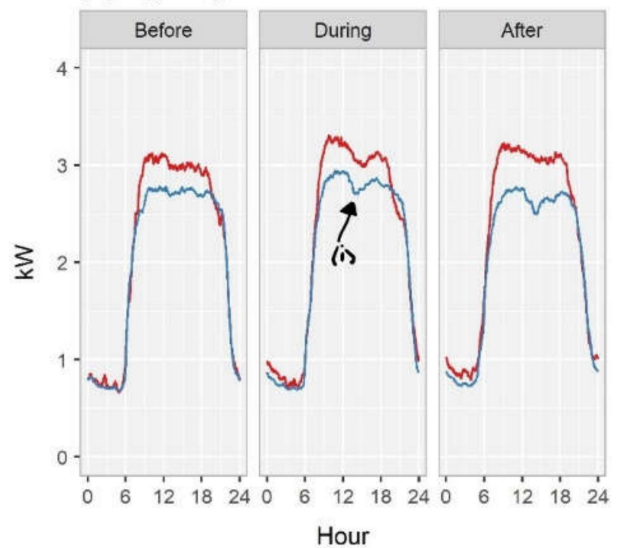

(b) Small Power

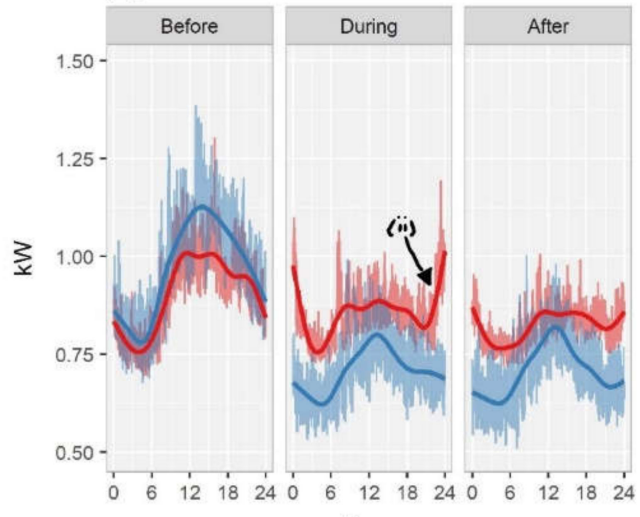

Hour

Study group - Control - Intervention

Figure 4. Average daily electricity profile for (a) lighting and (b) small power, comparing the control (RED) and intervention (BLUE) study groups for the study periods before (1 September31 October 2017), during (1 November 2017-31 January 2018) and after (1 February-30 April 2018) the behavior change intervention. Data shown as the average power for each minute of the day over the 3 month period.

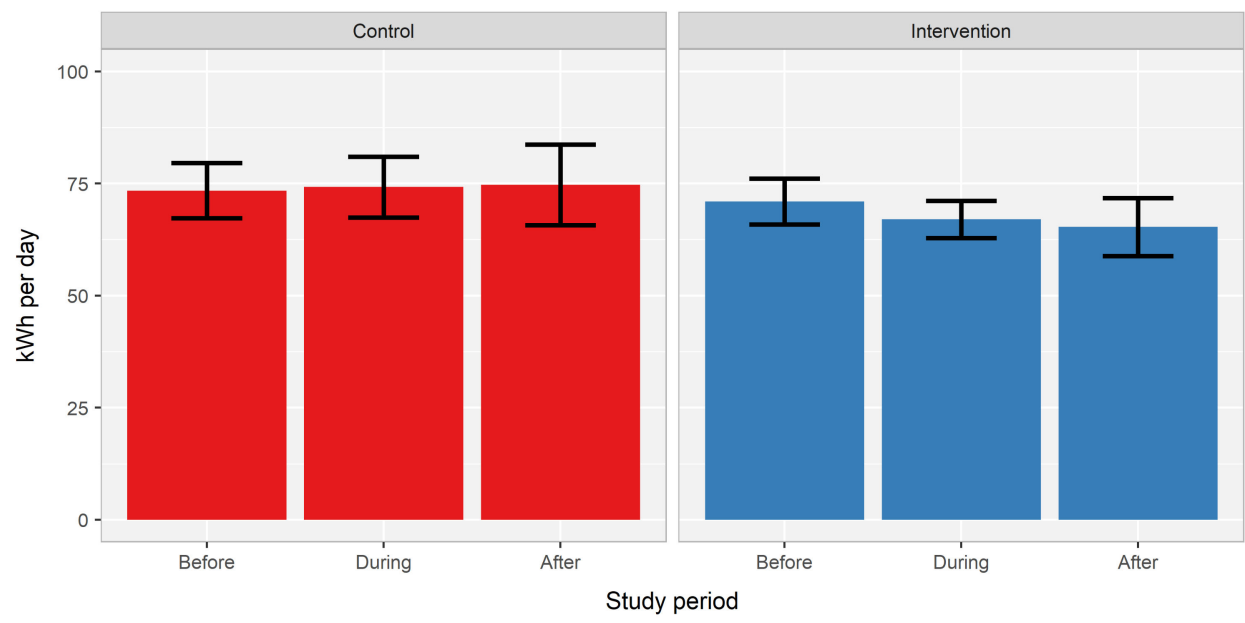

Figure 5. Combined electricity consumption per day ( $\mathrm{kWh} /$ day) for lighting and small power, comparing the control and intervention study groups for the study periods before (1 September31 October 2017), during (1 November 2017-31 January 2018) and after (1 February-30 April 2018) the behavior change intervention. 1 Standard Deviation of the mean is shown.

This study resulted in a combined electricity (lighting and small power), and associated carbon dioxide emissions and financial saving of $13 \%$ in both the study periods during (1 November 2017 to 31 January 2018) and after (1 February 2018 to 30 April 2018) the behavior change intervention, when compared to the control group. For the two intervention wards participating in this study this equated to total saving of $620 \mathrm{kWh}\left(1.6 \mathrm{kWh} / \mathrm{m}^{2}\right)$ and $226 \mathrm{kgCO}_{2} \mathrm{e}$ for the during and after study periods ( 6 months). The carbon factors used were 2018 company reporting figures as provided by the UK Government.

A Mann Whitney U-test showed a significant difference between the mean electricity consumption $(\mathrm{kWh})$ of the control and intervention groups both during the intervention $\left(p\right.$-value $\left.\leq 2 \times 10^{-16}\right)$ and after the intervention ( $p$-value $\left.\leq 2 \times 10^{-16}\right)$, which confirms the findings did not occur due to random error. A Mann Whitney U-test with a confidence level 
of $95 \%$ was used as the outcome variable (electricity consumption $\mathrm{kWh}$ ) was numerical with a non-normal distribution and two non-paired samples (control, intervention).

\subsection{Lighting}

As the light sensors do not distinguish between natural and artificial light, this approach is only valid for winter months and will over-predict the artificial "lights on" values during the summer months. Consequently, the data for the benchmark period before the intervention was disregarded from the study. However, as the intervention was run during the winter months this approach was suitable for analyzing the light data in the periods during and after the intervention.

Table 3 shows a summary of the total hours of "lights on" values classified into the main categories of interest for analysis, namely by the study periods of during and after the intervention and by study group, namely control and intervention groups.

Table 3. Summary table showing the count of "lights on" hours, comparing the control and intervention study groups for the study periods during (1 November 2017-31 January 2018) and after (1 February-30 April 2018) the behavior change intervention.

\begin{tabular}{ccccc}
\hline Study Period & Study Group & $\begin{array}{c}\text { Total Hours of } \\
\text { “Lights on" Values }\end{array}$ & $\begin{array}{c}\text { Number of Days } \\
\text { in Period }\end{array}$ & $\begin{array}{c}\text { Hours of “Lights } \\
\text { on” Ward Per Day }\end{array}$ \\
\hline During & Control & 1853 & 92 & 10 \\
During & Intervention & 1644 & 92 & 9 \\
After & Control & 1083 & 89 & 6 \\
After & Intervention & 998 & 89 & 5 \\
\hline
\end{tabular}

Consequently, this study produced an 11\% reduction in hours of "lights on" values during the behavior change intervention and an $8 \%$ reduction after the behavior change intervention, when compared to the control group. This equates to an average saving of one hour of artificial lighting per ward per day in the intervention group when compared to the control group, in the study periods during and after the intervention, as per the intervention's stated aim.

The results of the Pearson's Chi-square statistical analysis showed there was a statistically significant difference between control and the intervention groups both during the intervention ( $p$-value $\left.\leq 2 \times 10^{-16}\right)$ and after the intervention $\left(p\right.$-value $\left.\leq 2 \times 10^{-16}\right)$, which confirms the findings did not occur due to random error. The Pearson's Chi-square test was chosen as the data (binary on/off) is categorical with two non-paired samples (control, intervention) of over 20 units.

\section{Discussion}

The descriptive analysis of electricity used for lighting showed the intervention produced a $2 \%$ saving in electricity for lighting during the intervention and $10 \%$ saving after the intervention. The results of the Mann Whitney U-test show a significant difference between the mean power demand data $(\mathrm{kW})$ for lighting of the control and intervention groups both during the intervention $\left(p\right.$-value $\left.\leq 2 \times 10^{-16}\right)$ and after the intervention $\left(p\right.$-value $\left.\leq 2 \times 10^{-16}\right)$, which confirms the findings did not occur due to random error.

The results showed that both study groups used more electricity for lighting during the intervention than before the intervention, which as expected negatively correlates with the total hours of sunshine during these periods. Before the intervention (August, September, October) there was a total of $424 \mathrm{~h}$ of sunshine and during the intervention (November, December, January) there was a total of $194.5 \mathrm{~h}$ of sunshine [76].

The Met Office [76] reported a total of $330.6 \mathrm{~h}$ of sunshine for the period after the intervention (February, March, April), which is consistent with the findings from the intervention group that less electricity was used for lighting after the intervention than during the intervention. However, the control group used more electricity for lighting after study period than it had in either of the two previous study periods, which is not consistent with the reported hours of sunshine by the Met Office. 
The descriptive analysis of electricity used for small power showed the intervention produced a $29 \%$ saving in electricity for small power during the intervention and $16 \%$ saving after the intervention. The results of the Mann Whitney U-test show significant difference between the mean power demand data $(\mathrm{kW})$ for small power of the control and intervention groups both during the intervention ( $p$-value $\left.\leq 2 \times 10^{-16}\right)$ and after the intervention $\left(p\right.$-value $\left.\leq 2 \times 10^{-16}\right)$, which confirms the findings did not occur due to random error.

In both domestic and non-domestic settings energy behavior change was found to diminish when feedback stopped [37,38], which mirrors the findings here from the intervention group for the electricity for small power and electricity for lighting.

In relation to electricity for lighting, the behavior change took up to a month to take effect in the intervention group. The effect of the behavior change (reduction in electricity for lighting) then continued to increase for three months, peaking one month after the feedback stopped showing a delay in the effect. The effect of the behavior change then appeared to diminish over the following two months, although a reduction in electricity for lighting was still present.

In relation to electricity for small power, the effect of the behavior change (reduction in electricity for small power) took effect immediately and was sustained for four months, peaking one month after the feedback stopped. The effect of the behavior change then diminished over the following month and had appeared to have stopped by the sixth month. This study produced a total electricity (lighting and small power), and associated carbon dioxide emissions and financial saving of $13 \%$ in both the study periods during (1 November 2017 to 31 January 2018) and after (1 February 2018 to 30 April 2018) the behavior change intervention. For the two intervention wards participating in this study this equated to total saving of $620 \mathrm{kWh}\left(1.6 \mathrm{kWh} / \mathrm{m}^{2}\right)$ and $226 \mathrm{kgCO}_{2} \mathrm{e}$ for the during and after study periods (6 months).

There was a distinct rise in power demand for small power during the intervention period in the control group for approximately $4 \mathrm{~h}$ during the night time; starting around 22:00:00 and ending around 02:00:00. This appears to be due to the use of electrical equipment, such as portable space heaters in the control group that was not used in the intervention group. Use of electrical space heaters is a common practice with nursing staff, albeit prohibited in the Trust's Energy Policy, due the risk of fire on the wards. Whilst this study did not directly target the use of space heaters, one of the actions in the behavior change intervention was to 'Turn off equipment', which included space heaters. This highlights the potential tension between thermal comfort and energy saving, which was out of scope for this study.

The descriptive analysis from the light sensors showed that the intervention group switched lights on for $11 \%$ less hours than the control group during the intervention and $8 \%$ less after the intervention, which fits the findings from the literature review that energy behavior change was found to diminish when feedback stopped [36,37]. The results of the Pearson's Chi-square statistical analysis showed there is a statistically significant difference between the control and the intervention groups both during the intervention $\left(p\right.$-value $\left.\leq 2 \times 10^{-16}\right)$ and after the intervention $\left(p\right.$-value $\left.\leq 2 \times 10^{-16}\right)$, which confirms the findings did not occur due to random error. These savings equate to an average saving of one hour per ward per day in the intervention group compared to the control group in the study periods during and after the intervention, which is consistent with the Operation TLC secondary action of "Implement quiet time for an hour after lunch".

The finding for the light data (11\% saving) during the intervention is higher than the findings for the electricity data for lighting ( $2 \%$ saving). An explanation for this may be the total reported hours of sunshine, which are significantly lower (194.5 h) during the intervention (due to time of year) than the other study periods [76]. Whilst the light data is specific to the patient rooms on the ward participating in the study, the electricity for lighting $(\mathrm{kWh})$ also includes lighting in the other areas of the study wards, including corridors, offices and staff rooms, which may have been left on by staff in the other ward 
areas as a result of limited sunshine during this period. After the intervention the results from the light data and electricity for lighting $(\mathrm{kWh})$ continue to show a positive reduction, and the amount for the light data ( $8 \%$ saving) is consistent when compared to the electricity for lighting data ( $9 \%$ saving). Again, this may reflect the increase in hours of sunshine $(330.6 \mathrm{~h})$ for this study period, which may have resulted in staff turning lights off in the other areas of the ward.

From feedback during the staff focus groups, the staff in both the control and intervention groups felt the lighting on the study wards was too bright when the artificial lights were on and too dark when the blinds were closed during the day time for adaption to summer over-heating. This confirmed there was scope to turn lights off in the wards, which was supported by the results from the quantitative data.

From the comfort surveys, the control and intervention group reported the highest percentage in the 'neither bright nor dim' score during and after the intervention study periods, which show that lighting was not a significant concern for staff on the wards. This implies that the staff on the intervention ward turned lights off as a result of the behavior change intervention to improve the environment for their patients.

\section{Conclusions}

This study produced a total electricity (lighting and small power), and associated carbon dioxide emissions and financial saving of $13 \%$ in both the study periods during (1 November 2017 to 31 January 2018) and after (1 February 2018 to 30 April 2018) the behavior change intervention.

The descriptive analysis from the light sensors showed that the intervention group switched lights on for $11 \%$ less hours than the control group during the intervention and $8 \%$ less after the intervention. This equates to an average saving of one hour per ward per day in the intervention group compared to the control group in the study periods during and after the intervention, which is consistent with the Operation TLC secondary action of "Implement quiet time for an hour after lunch". This is confirmed by the daily power profiles for electricity from lighting, which show a distinctive dip in power demand after lunchtime in the intervention group but not in the control group. It should be noted that the lifetime of CFL lighting can be impacted by cycling on and off [77], the impact of which was not considered here.

The study also showed that the nursing staff in the intervention group not only had a heightened awareness of energy use as a result of the evidence based information provided during the intervention but were also found to actively implement the Trust Energy Policy when compared to the control, particularly in relation to the prohibited use of space heating on the wards. The use of portable electrical heaters was evident in the control wards, which from a health and safety and energy perspective should be addressed. In October 2020, the NHS published its "Delivering a 'Net Zero' National Health Service" report [78] which outlined its delivery plan. Amongst the proposals are the embedding of sustainability across the NHS and a changing of the NHS Constitution to make sustainability a key responsibility of all staff. This directly links to several aspects of this study, but the use of electrical heaters in particular. Whilst intervention effects were observed to continue after the intervention period there was a gradual reduction in scale. This indicates such an intervention has a limited time effect and needs to be repeated to sustain impact and fully embed change in practices.

In conclusion, the contribution to existing knowledge resulting from this case study is threefold. Substantively, this study has identified that running the energy behavior change intervention in a NHS community hospital produced a total electricity (lighting and small power) saving of $13 \%$. Theoretically, this study identified the social, organizational and contextual factors in the ward environment affected by the energy behavior change intervention. Methodologically, this study proposed a new model for running a behavior change intervention in hospitals. 
Author Contributions: Conceptualization, L.S. and S.K.; methodology, L.S.; software, M.H. and L.S.; validation, L.S. and M.H.; formal analysis, L.S.; investigation, L.S.; resources, L.S.; data curation, L.S.; writing-original draft preparation, L.S.; writing-review and editing, L.S., P.J., S.K. and M.H.; visualization, L.S. and M.H.; supervision, S.K. and P.J.; project administration, L.S.; funding acquisition, S.K. All authors have read and agreed to the published version of the manuscript.

Funding: This research received no external funding.

Institutional Review Board Statement: Ethics approval was granted for the study by the Health Research Authority, 'Sustainability benefits of behavioural change in NHS Trusts', IRAS 223344, REC 17/HRA/1897. No personal data was collected from patients, the level of patient in-formation was limited to defining if a studied patient bay was male or female.

Informed Consent Statement: Nurses provided written consent for participation in the qualitative aspect of the study.

Acknowledgments: We would especially like to thank the Trust staff involved in this study, particularly the Ward Managers, nursing staff and healthcare support workers for all their hard work and kindness. Finally, we would like to thank the other stakeholders involved in this study including the PFI owner, PFI management company, Hard and Soft facilities suppliers and their teams on site who readily joined in with the project.

Conflicts of Interest: The authors declare no conflict of interest.

\section{References}

1. Climate Change Act. Her Majesty's Stationery Office [Online]. London. 2008. Available online: http://www.legislation.gov.uk/ ukpga/2008/27/pdfs/ukpga_20080027_en.pdf (accessed on 4 October 2021).

2. Gill, M.; Stott, R. Health professionals must act to tackle climate change. Lancet 2009, 374, 1953-1955. [CrossRef]

3. Watts, N.; Adger, W.N.; Agnolucci, P.; Blackstock, J.; Byass, P.; Cai, W.; Chaytor, S.; Colbourn, T.; Collins, M.; Cooper, A.; et al. Health and climate change: Policy responses to protect public health. Lancet 2015, 386, 1861-1914. [CrossRef]

4. NHS Sustainable Futures. 2021. Available online: https://www.networks.nhs.uk/nhs-networks/nhs-sustainable-futures/about-us (accessed on 5 October 2021).

5. Hawkes, N. BMJ 2016;352;i605, Sixty Seconds on ... Greening the NHS. 2016. Available online: https://www.bmj.com/content/ bmj/352/bmj.i605.full.pdf (accessed on 5 October 2021).

6. Estates and Returns Information Collection (ERIC). 2016; p. 21, published 11 October 2016. Available online: https: / / assets.publishing.service.gov.uk/government/uploads/system/uploads/attachment_data/file/559126/est-ret-info-col-20 15-2016-Report.pdf (accessed on 5 October 2021).

7. Department of Health. EnCO2de 2015-Making Energy Work in Healthcare. Part A: Policy E Management; Health Technical Memorandum 07-02; Department of Health: London, UK, 2015. Available online: https://www.gov.uk/government/publications/ making-energy-work-in-healthcare-htm-07-02 (accessed on 5 October 2021).

8. The Carbon Trust. CTG056 Creating an Awareness Campaign; The Carbon Trust: London, UK, 2013.

9. Morgenstern, P.; Raslan, R.; Huebner, G. Applicability, potential and limitations of staff-centred energy conservation initiatives in English hospitals. Energy Effic. 2016, 9, 27-48. [CrossRef]

10. Swain, E.; McCauley, S.; Edberg, S.; Mwaura, G.; Gutierrez, M.J. Multisolving at the Intersection of Health and Climate: Lessons from Success Stories. 2018. Available online: https://www.climateinteractive.org/wp-content/uploads/2018/02/Multisolvingat-the-Intersection-of-Health-and-Climate-1.pdf (accessed on 4 October 2021).

11. Manika, D.; Gregory-Smith, D.; Wells, V.; Comerford, L.; Aldrich-Smith, L. Linking environmental sustainability and healthcare: The effects of an energy savings intervention in two hospitals. Int. J. Bus. Sci. Appl. Manag. 2016, 11, 32-54.

12. Abrahamse, W.; Steg, L.; Vlek, C.; Rothengatter, T. A review of intervention studies aimed at household energy conservation. J. Environ. Psychol. 2005, 25, 273-291. [CrossRef]

13. Lo, S.H.; Peters, G.J.Y.; Kok, G. A Review of Determinants of and Interventions for Pro-environmental Behaviors in Organizations. J. Appl. Soc. Psychol. 2012, 42, 2933-2967. [CrossRef]

14. McGain, F.; Naylor, C. Environmental sustainability in hospitals-A systematic review and research agenda. J. Health Serv. Res. Policy 2014, 19, 245-252. [CrossRef] [PubMed]

15. Young, W.; Davis, M.; McNeill, I.M.; Malhotra, B.; Russell, S.; Unsworth, K.; Clegg, C.W. Changing Behaviour: Successful Environmental Programmes in the Workplace. Bus. Strategy Environ. 2015, 24, 689-703. [CrossRef]

16. Steg, L.; Vlek, C. Encouraging pro-environmental behaviour: An integrative review and research agenda. J. Environ. Psychol. 2009, 29, 309-317. [CrossRef]

17. Williams, J.; Knight, I.; Griffiths, A. Hospital energy performance: New indicators for UK National Health Service estate. Build. Serv. Eng. Res. Technol. 1999, 20, 9-12. [CrossRef] 
18. Saidur, R.; Hasanuzzaman, M.; Yogeswaran, S.; Mohammed, H.A.; Hossain, M.S. An end-use energy analysis in a Malaysian public hospital. Energy 2010, 35, 4780-4785. [CrossRef]

19. Burpee, H.; McDade, E. Comparative Analysis of Hospital Energy Use: Pacific Northwest and Scandinavia. HERD Health Environ. Res. Des. J. 2014, 8, 20-44. [CrossRef] [PubMed]

20. Balaras, C.A.; Dascalaki, E.; Gaglia, A. HVAC and indoor thermal conditions in hospital operating rooms. Energy Build. 2007, 39, 454-470. [CrossRef]

21. Lomas, K.J.; Ji, Y. Resilience of naturally ventilated buildings to climate change: Advanced natural ventilation and hospital wards. Energy Build. 2009, 41, 629-653. [CrossRef]

22. Short, C.A.; Lomas, K.J.; Woods, A. Design strategy for low-energy ventilation and cooling within an urban heat island. Build. Res. Inf. 2004, 32, 187-206. [CrossRef]

23. Buonomano, A.; Calise, F.; Ferruzzi, G.; Palombo, A. Dynamic energy performance analysis: Case study for energy efficiency retrofits of hospital buildings. Energy 2014, 78, 555-572. [CrossRef]

24. Topf, M. Psychological Explanations and Greening Hospitals. Health Care Manag. Rev. 2005, 30, 2-8. [CrossRef] [PubMed]

25. Sawyer, L.K. Sustainability Benefits of Energy Behaviour Change in an NHS Trust; University of Southampton: Southampton, UK, 2020.

26. Sawyer, L.; Kemp, S.; James, P.; Harper, M. Noisy and restless: $24 \mathrm{~h}$ in an NHS community hospital ward, a qualitative and quantitative analysis of the patient environment. Build. Environ. 2020, 175, 106795. [CrossRef]

27. Mulville, M.; Jones, K.; Huebner, G.; Powell-Greig, J. Energy-saving occupant behaviours in offices: Change strategies. Build. Res. Inf. 2016, 45, 861-874. [CrossRef]

28. Steg, L. Promoting household energy conservation. Energy Policy 2008, 36, 4449-4453. [CrossRef]

29. Carrico, A.; Riemer, M. Motivating energy conservation in the workplace: An evaluation of the use of group-level feedback and peer education. J. Environ. Psychol. 2011, 31, 1-13. [CrossRef]

30. Macarulla, M.; Casals, M.; Gangolells, M.; Forcada, N. Reducing energy consumption in public buildings through user awareness. In European Conference on Product and Process Modelling; Taylor \& Francis: London, UK, 2015; pp. 637-641.

31. Fisher, J.; Irvine, K. Reducing energy use and carbon emissions: A critical assessment of small-group interventions. Energies 2016, 9, 172. [CrossRef]

32. Siero, F.W.; Bakker, A.B.; Dekker, G.B.; Van Den Burg, M.T.C. Changing Organizational Energy Consumption Behaviour Through Comparative Feedback. J. Environ. Psychol. 1996, 16, 235-246. [CrossRef]

33. Gulbinas, R.; Taylor, J.E. Effects of real-time eco-feedback and organizational network dynamics on energy efficient behavior in commercial buildings. Energy Build. 2014, 84, 493-500. [CrossRef]

34. Ornaghi, C.; Costanza, E.; Kittley-Davies, J.; Bourikas, L.; Aragon, V.; James, P. The effect of behavioural interventions on energy conservation in naturally ventilated offices. Energy Econ. 2018, 74, 582-591. [CrossRef]

35. Nolan, J.M.; Schultz, P.W.; Cialdini, R.B.; Goldstein, N.J.; Griskevicius, V. Normative Social Influence is Underdetected. Pers. Soc. Psychol. Bull. 2008, 34, 913-923. [CrossRef]

36. Dwyer, W.O.; Leeming, F.C.; Cobern, M.K.; Porter, B.E.; Jackson, J.M. Critical Review of Behavioral Interventions to Preserve the Environment: Research Since 1980. Environ. Behav. 1993, 25, 275-321. [CrossRef]

37. Darby, H.; Elmualim, A.; Clements-Croome, D.; Yearley, T.; Box, W. Influence of occupants' behaviour on energy and carbon emission reduction in a higher education building in the UK. Intell. Build. Int. 2016, 8, 157-175. [CrossRef]

38. Murtagh, N.; Nati, M.; Headley, W.R.; Gatersleben, B.; Gluhak, A.; Imran, M.A.; Uzzell, D. Individual energy use and feedback in an office setting: A field trial. Energy Policy 2013, 62, 717-728. [CrossRef]

39. Abrahamse, W.; Steg, L.; Vlek, C.; Rothengatter, T. The effect of tailored information, goal setting, and tailored feedback on household energy use, energy-related behaviors, and behavioral antecedents. J. Environ. Psychol. 2007, 27, 265-276. [CrossRef]

40. Staddon, S.C.; Cycil, C.; Goulden, M.; Leygue, C.; Spence, A. Intervening to change behaviour and save energy in the workplace: A systematic review of available evidence. Energy Res. Soc. Sci. 2016, 17, 30-51. [CrossRef]

41. Handgraaf, M.J.; Jeude, M.A.V.L.D.; Appelt, K.C. Public praise vs. private pay: Effects of rewards on energy conservation in the workplace. Ecol. Econ. 2012, 86, 86-92. [CrossRef]

42. Littleford, C. Energy Use by Individual Office Workers: Psychological and Contextual Influences on Behaviour. Ph.D. Thesis, Loughborough University, Loughborough, UK, 2013.

43. Coleman, M.J.; Irvine, K.N.; Lemon, M.; Shao, L. Promoting behaviour change through personalized energy feedback in offices. Build. Res. Inf. 2013, 41, 637-651. [CrossRef]

44. De Groot, J.I.M.; Steg, L. Morality and prosocial behavior: The role of awareness, responsibility, and norms in the norm activation model. J. Soc. Psychol. 2009, 149, 425-449. [CrossRef] [PubMed]

45. Djordjevic, A.; Cotton, D. Communicating the sustainability message in higher education institutions. Int. J. Sustain. High. Educ. 2011, 12, 381-394. [CrossRef]

46. Cox, A.; Higgins, T.; Gloster, R.; Foley, B.; Darnton, A. The Impact of Workplace Initiatives on Low Carbon Behaviours; Social Research; Scottish Government: Edinburgh, UK, 2012; ISBN 9781780457581.

47. Morgenstern, P.; Li, M.; Raslan, R.; Ruyssevelt, P.; Wright, A. Benchmarking acute hospitals: Composite electricity targets based on departmental consumption intensities? Energy Build. 2016, 118, 277-290. [CrossRef]

48. Dunphy, J.L. Healthcare professionals' perspectives on environmental sustainability. Nurs. Ethics 2014, 21, 414-425. [CrossRef] 
49. Bedwell, B.; Leygue, C.; Goulden, M.; McAuley, D.; Colley, J.; Ferguson, E.; Banks, N.; Spence, A. Apportioning energy consumption in the workplace: A review of issues in using metering data to motivate staff to save energy. Technol. Anal. Strateg. Manag. 2014, 26, 1196-1211. [CrossRef]

50. Ryan-Fogarty, Y.; O’Regan, B.; Moles, R. Greening healthcare: Systematic implementation of environmental programmes in a university teaching hospital. J. Clean. Prod. 2016, 126, 248-259. [CrossRef]

51. Bull, R.; Lemon, M.; Fleming, P.D.; Stuart, G.; Everitt, D. Digitally Engaging and Empowering Employees for Energy Demand Reduction: A New Approach for the Next Generation? In ACEEE Summer Study on Energy Efficiency in Buildings; American Council for an Energy-Efficient Economy: Pacific Grove, CA, USA, 2014; pp. 7-65.

52. Goulden, M.; Spence, A. Caught in the middle: The role of the Facilities Manager in organisational energy use. Energy Policy 2015, 85, 280-287. [CrossRef]

53. Tudor, T. The UK National Health Service (NHS) and the sustainability agenda. Waste Resour. Manag. 2013, 166, 38-42. [CrossRef]

54. Menzes, A.C.; Tetlow, R.; Beaman, C.P.; Cripps, A.; Bouchlaghem, D.; Buswell, R. Assessing the impact of occupant behaviour on the electricity consumption for lighting and small power in office buildings. In Proceedings of the International Conference on Innovation in Architecture, Engineering \& Construction, Sao Paulo, Brazil, 15-17 August 2012; pp. 1-12.

55. Chatterton, T. An Introduction to Thinking about 'Energy Behaviour': A Multi-Model Approach; DECC: London, UK, 2011. Available online: https://assets.publishing.service.gov.uk/government/uploads/system/uploads/attachment_data/file/48256/3887 -intro-thinking-energy-behaviours.pdf (accessed on 5 October 2021).

56. Harris, N.; Pisa, L.; Talioaga, S.; Vezeau, T. Hospitals going green: A holistic view of the issue and the critical role of the nurse leader. Holist. Nurs. Pract. 2009, 23, 101-111. [CrossRef]

57. Festinger, L. A Theory of Cognitive Dissonance; Row Peterson \& Co.: Evanston, IL, USA, 1957.

58. Rothenberg, S. Knowledge Content and Worker Participation in Environmental Management at NUMMI. J. Manag. Stud. 2003, 40, 1783-1802. [CrossRef]

59. McDiarmid, M.A. Chemical Hazards in Health Care: High Hazard, High Risk, but Low Protection. Ann. N. Y. Acad. Sci. 2006, 1076, 601-606. [CrossRef]

60. Cotton, D.R.E.; Miller, W.; Winter, J.; Bailey, I.; Sterling, S. Developing students' energy literacy in higher education. Int. J. Sustain. High. Educ. 2015, 16, 456-473. [CrossRef]

61. Tudor, T.L.; Barr, S.W.; Gilg, A.W. A novel conceptual framework for examining environmental behavior in large organizations: A case study of the Cornwall National Health Service (NHS) in the United Kingdom. Environ. Behav. 2008, 40, 426-450. [CrossRef]

62. Tetlow, R.M.; van Dronkelaar, C.; Beaman, C.P.; Elmualim, A.A.; Couling, K. Identifying behavioural predictors of small power electricity consumption in office buildings. Build. Environ. 2015, 92, 75-85. [CrossRef]

63. CRAN. RStudio Desktop 1.2.1335 [Online]. 2018. Available online: https://www.rstudio.com/products/rstudio/download/ (accessed on 2 April 2018).

64. Michie, S.; Van Stralen, M.M.; West, R. The behaviour change wheel: A new method for characterising and designing behaviour change interventions. Implement. Sci. 2011, 6, 42. [CrossRef] [PubMed]

65. Royal College of Nursing. Going Upstream: Nursing's Contribution to Public Health [Online]. London. 2012. Available online: https: / / www.choiceforum.org/docs/run.pdf (accessed on 5 October 2021).

66. Park, M.J.; Yoo, J.H.; Cho, B.W.; Kim, K.T.; Jeong, W.-C.; Ha, M. Noise in hospital rooms and sleep disturbance in hospitalized medical patients. Environ. Health Toxicol. 2014, 29, e2014006. [CrossRef] [PubMed]

67. Jolley, J. Introducing Research and Evidence-Based Practice for Nurses; Pearson: Harlow, UK, 2009.

68. Lally, P.; van Jaarsveld, C.H.M.; Potts, H.W.W.; Wardle, J. How are habits formed: Modelling habit formation in the real world. Eur. J. Soc. Psychol. 2010, 40, 998-1009. [CrossRef]

69. Tableau. Tableau Software [Online]. 2003. Available online: https:/ /www.tableau.com/en-gb (accessed on 1 August 2018).

70. The King's Fund. Mental Health under Pressure [Online]. London. 2015. Available online: http://www.kingsfund.org.uk/sites/ files/kf/field/field_publication_file/mental-health-under-pressure-nov15.pdf (accessed on 5 October 2021).

71. Appleby, J. Spending on Health and Social Care over the Next 50 Years Why Think Long Term? The Kings Fund: London, UK, 2013; pp. 1-68. ISBN 9781909029033. Available online: https://www.kingsfund.org.uk/publications/spending-health-and-social-careover-next-50-years (accessed on 5 October 2021).

72. LEM. Product Datasheet: LEM AC Current Transducer AT-B10 [Online]. 2018. Available online: https://www.lem.com/sites/ default/files/products_datasheets/at-b10.pdf (accessed on 17 May 2018).

73. LI-COR. Product Datasheet: Li-Cor Terrestrial Radiation Sensors [Online]. 2007. Available online: https://www.licor.com/ documents / 8yfdtw1rs27w93vemwp6 (accessed on 17 May 2017).

74. Morgenstern, P. Understanding Hospital Electricity Use: An End-Use(r) Perspective. Ph.D. Thesis, University College London, London, UK, 2016.

75. Energy Consumption. Guide 72. Energy Consumption in Hospitals, DETR, Crown Copyright. 1999, pp. 1-16. Available online: https: / /www.cibse.org/getmedia/a9ab0fc1-97ed-4048-b6b5-936116334bc4/ECG72-Energy-Consumption-in-Hospitals1999.pdf.aspx (accessed on 5 October 2021).

76. The Met Office. Weather Observations Website [Online]. 2018. Available online: https://wow.metoffice.gov.uk/ (accessed on 24 April 2018). 
77. Jump, C.; Hirsch, J.J.; Peters, J.; Moran, D. Welcome to the Dark Side: The Effect of Switching on CFL Measure Life. Available online: https:/ /www.aceee.org/files/proceedings/2008/data/papers/2_111.pdf (accessed on 5 October 2021).

78. Delivering a 'Net Zero' National Health Service. October 2020. Available online: https: / www.england.nhs.uk/greenernhs / publication/delivering-a-net-zero-national-health-service/ (accessed on 5 October 2021). 